\title{
Modeling The Multiregional Economy: Integrating Econometric and Input-Output Models \#
}

\author{
John R. Kort and Joseph V. Cartwright*
}

\section{INTRODUCTION}

During the last decade, considerable research has been devoted to modeling the linkages within the national economy in a more disaggregate fashion. In addition to more detailed industry models, a number of multiregional models have been constructed to capture the Nation-to-region, region-to-Nation, and region-to-region linkages in an economy. Both multiregional input-output $(\mathrm{I} / \mathrm{O})$ and multiregional econometric models have been developed for the U.S. and other countries for this purpose. ${ }^{1}$

Applications of $\mathrm{I} / \mathrm{O}$ models have typically been in providing detailed interindustry impacts of final demand changes without reference to the time paths of those impacts. In contrast, typical applications of multiregional econometric models have been in providing the dynamic time paths of regional variables at a relatively industrially-aggregate level. While there is considerable demand for both types of models independent of one another, there are cases where $\mathrm{I} / \mathrm{O}$ and econometric models can be used in a complementary fashion, where the advantages of both are combined. ${ }^{2}$ This is particularly true for impact analysis where, for instance, industryspecific final demand changes (usually unaccounted for in econometric models) are translated into information that is acceptable to an econometric model. Thus, both intertemporal and detailed interindustry impacts are modeled.

Except for some national models and a few single-region models, very little research has been conducted on using I/O and econometric models in a complementary fashion for impact analysis. Accordingly, the purpose of this paper is to demonstrate how such an integration may be accomplished at the multiregional level. After reviewing two possible approaches to $\mathrm{I} / \mathrm{O}$-econometric model integration, we present a methodology that has been developed at the Bureau of Economic Analysis (BEA) that can be used to link $\mathrm{I} / \mathrm{O}$ and econometric models for use in impact analysis. The

\#Views expressed are solely the authors' and do not necessarily reflect those of the Department of Commerce. The authors' acknowledge the contributions of Kenneth Ballard in formulating the application described in this paper, and wish to thank A. Ray Grimes, Jr. and two anonymous referees for useful comments on an earlier draft. A longer version of this paper (originally presented at the 1981 Southern Regional Science Meetings), which discusses general multiregional modeling methodology, is available from the authors on request.

* Regional Economic Analysis Division, Bureau of Economic Analysis, U.S. Department of Commerce, Washington, D.C. 20230 . 
methodology uses three models: a regional I/O model (RIMS II-Regional Input-Output Modeling System), a national I/O table (BEA I/O), and a multiregional econometric model (NRIES-National Regional Impact Evaluation System). In addition to discussing the methodology of integrating the three models, we describe the RIMS II and NRIES models, and present an application of the methodology.

\section{INTEGRATING ECONOMETRIC AND INPUT-OUTPUT MODELS}

\section{Embedding Approach}

One approach to integrating $\mathrm{I} / \mathrm{O}$ and econometric models is to embed intermediate demand relationships within an econometric model. This approach takes advantage of the characteristics of an $\mathrm{I} / \mathrm{O}$ model-where intermediate demands and final demands are identified and sum to gross output-and the characteristics of an econometric model-where the econometric model has the ability to forecast final demand. The embedding approach can be viewed as composed of two distinct aspects. In the first aspect, econometrically estimated forecasts of final demand become the exogenous inputs into an $\mathrm{I} / \mathrm{O}$ model. In the second aspect, selected output variables of an $\mathrm{I} / \mathrm{O}$ model serve as some of the inputs to an econometric model.

To illustrate the first aspect of the embedding approach, we begin with the $\mathrm{I} / \mathrm{O}$ accounting identity that intermediate plus final demand equals gross output:

$$
X_{i}=\sum_{j} X_{i j}+\underset{S}{\Sigma} Y_{i s}
$$

where $\mathrm{X}_{\mathrm{i}}$ is total gross output for industry $\mathrm{i}$; $\mathrm{X}_{\mathrm{ij}}$ is the intermediate demand for the $\mathrm{i}^{\mathrm{th}}$ industry's output by the $\mathrm{j}^{\text {th }}$ industry; and for the $\mathrm{i}^{\text {th }}$ industry's output, $Y_{\text {is }}$ is final demand in sector $\mathrm{s}$, ( $\mathrm{s}=$ consumption $\left(\mathrm{C}_{\mathrm{i}}\right)$, investment $\left(\mathrm{I}_{\mathrm{i}}\right)$, government $\left(\mathrm{G}_{\mathrm{i}}\right)$, and exports $\left.\left(\mathrm{E}_{\mathrm{i}}\right)\right)$. An equation similar to (1) holds for total output and total final demand.

$$
\mathrm{X} .=\sum_{\mathrm{j}} \mathrm{X}_{\mathrm{j}}+\underset{\mathrm{S}}{\Sigma} \mathrm{Y}_{. \mathrm{s}}
$$

where the dot (.) refers to summing over the $\mathrm{i}^{\text {th }}$ subscript.

Dividing intermediate demands $\left(\mathrm{X}_{\mathrm{ij}}\right)$ by column-total output $\left(\mathrm{X}_{\mathrm{j}}\right)$ yields the direct, or technical coefficients $\left(\mathrm{a}_{\mathrm{ij}}\right)$ and equation (1) may be rewritten as,

$$
X_{i}-\sum_{j} a_{i j} X_{j}=Y_{i s}
$$


This equation forms the logical basis for the first aspect of the embedding approach. In particular, an econometric model is used to forecast the levels of the components of total final demand, as in the following equation:

$\hat{\mathrm{Y}}_{. \mathrm{s}}=\mathrm{f}_{\mathrm{s}}\left(\mathrm{Z}_{\mathrm{s} 1}, \mathrm{Z}_{\mathrm{s} 2}, \ldots, \mathrm{Z}_{\mathrm{sn}}\right)$

where the s subscript again refers to consumption, investment, etc., and the $Z_{\mathrm{s}}$ 's are exogenous variables used to predict total final demand in sector s.

Frequently, industry-specific final demand is then predicted by using base-year ratios of industry-specific to total final demand obtained from either a survey-based or a nonsurvey based I/0 table in the following manner:

$$
\hat{\mathrm{Y}}_{\mathrm{is}}=\mathrm{g}_{\mathrm{s}}\left(\hat{\mathrm{Y}}_{. \mathrm{s}},\left(\mathrm{Y}_{\mathrm{is}} / \mathrm{Y}_{\mathrm{s}}\right)^{\text {base }}\right)
$$

where equation (5) often takes the simple multiplication form, that is,

$$
\hat{\mathrm{Y}}_{\mathrm{is}}=\hat{\mathrm{Y}}_{\mathrm{s}} \times\left(\mathrm{Y}_{\mathrm{is}} / \mathrm{Y}_{\mathrm{s}}\right)^{\text {base }}
$$

Having thus specified interindustry relationships $\left(\mathrm{a}_{\mathrm{ij}}\right.$ 's) and forecasted final demand components $\left(\hat{\mathrm{Y}}_{\mathrm{is}}, \mathrm{s}=\hat{\mathrm{C}}_{\mathrm{i}}, \hat{\mathrm{I}}_{i}, \hat{\mathrm{G}}_{\mathrm{i}}, \hat{\mathrm{E}}_{\mathrm{i}}\right)$, industry-specific output forecasts can be made through the following equation:

$$
\hat{\mathrm{X}}_{\mathrm{i}}=\mathrm{h}_{\mathrm{s}}\left(\mathrm{a}_{\mathrm{ij}}, \hat{\mathrm{Y}}_{\mathrm{is}}\right)
$$

Equation (7) highlights the procedures of the first aspect of the embedding approach: econometric forecasts of final demand and interindustry relationships are used to forecast industry output.

The second aspect of the embedding approach uses some of the output information from the $\mathrm{I} / 0$ model in constructing the explanatory variables (the $Z$ variables) in equation (4). For example, several embedded-approach models estimate income and employment as functions of $\mathrm{I} / 0$-estimated output; in turn, the income and employment estimates are used as exogenous variables in the econometric model to estimate a final demand component (e.g., consumption) for the next iteration of the sverall model. This makes the model simultaneous in its input-output and econometric aspects.

The embedded approach has been employed at the national level for the U.S., Mexico, and Canada, for example-Almon, et al. (1974), Preston (1972 and 1975), Sequy and Ramirez (1975), and Bodkin (1976)—and at the single-region level for the States of Washington, Ohio, and Massachusetts-Bourque, et al. (1977), L'Esperance (1975), and Treyz, et al. (1980). The technique of embedding $\mathrm{I} / 0$ relationships into an econometric model at the multiregional model has only recently been proposed by Treyz (1980), in part based on a methodology developed by Stevens, et al. (1980). 


\section{Linking Approach}

A second approach to integrating $\mathrm{I} / 0$ and econometric models is to link $\mathrm{I} / 0$ model outputs to an econometric model. ${ }^{3}$ This approach also takes advantage of the characteristics of both types of models, but, unlike the embedded approach, it has no econometrically-driven aspect. That is, the linking approach is not simultaneous in its input-output and econometric aspects. However, as will be argued later, this is an advantage of the approach, particularly for impact analysis.

To illustrate the linking approach, equation (3) may be rewritten in matrix notation as,

$$
\mathrm{X}-\mathrm{AX}=\mathrm{Y}
$$

or, utilizing the identity matrix,

$$
(\mathrm{I}-\mathrm{A}) \mathrm{X}=\mathrm{Y}
$$

Letting B denote $(\mathrm{I}-\mathrm{A})^{-1}$, and solving for changes in output in terms of final demand changes yields,

$$
\Delta \mathrm{X}=\mathrm{B} \cdot \Delta \mathrm{Y}
$$

The linking approach uses a regional I/0 model to estimate the total requirements (with total final demand, including households, exogenous) matrix $\mathrm{B}$, and then solving for $\Delta \mathrm{X}$ provides industrially-disaggregated estimates of the initial changes in output resulting from any final demand change. The second step involves the conversion of the output changes to changes in value added. ${ }^{4}$ This is accomplished by obtaining value addedto-output ratios, and premultiplying the right-hand side of (8) by these ratios:

$$
\Delta \mathrm{Q}=\mathrm{R} \cdot \mathrm{B} \cdot \Delta \mathrm{Y}
$$

where:

$$
\mathrm{R}=\frac{\mathrm{Q}}{\mathrm{X}}
$$

and,

$\mathrm{Q}=$ output (GNP or value added definition)

$\mathrm{X}=$ output $(\mathrm{I} / \mathrm{O}$ definition $)$

The third step in the linking approach involves aggregating the initial changes in value added to the industrial detail of the econometric model, and using them, in combination with certain exogenous assumptions, as inputs into the econometric model. Finally, two solutions of the econometric model are completed-one where normal growth trends in the regional 
economies are forecasted and one where adjustments $\left(\Delta Q_{i}\right)$ are incorporated into the mudel to provide an impact solution. The values of major aggregates of the two solutions are then compared to assess the total impacts of the exogenous final demand changes.

The linking approach thus differs from the embedding approach in an important aspect. Since the initial impacts from the $\mathrm{I} / \mathrm{O}$ model are estimated using the $B$ matrix with households exogenous, and since econometric models typically do not contain detailed interindustry linkages, the $\mathrm{I} / \mathrm{O}$ and econometric models complement each other in a fashion that avoids double counting. That is, each model independent of one another represents an incomplete set of regional accounts. The I/O model has no interregional linkages, investment and household spending are exogenous, and intertemporal effects are unaccounted for. It does, however, provide a fairly complete and detailed set of interindustry linkages, and does translate final demand changes into value-added changes. The econometric model completes the accounting framework by providing the induced, interregional, and intertemporal aspects. The implications of other differences between the two approaches are discussed below.

\section{Advantages and Limitations of the Approaches}

There are two major advantages of the embedded approach in specifying multiregional models. First, forecasts of (and impacts on) output, income, and employment can be made for a larger number of industries than with most purely econometric models. Second, the industrially disaggregated forecasts require estimating only four variables (C., I., G., and E.). However, several models do disaggregate final demand components into subcomponents in order to estimate better the aggregate component; for example, in Bourque, et al., total investment is the sum of the following separately estimated subcomponents: residential investment, nonresidential investment in structures, investment in equipment, and inventory change. ${ }^{5}$

The several potential limitations of the embedded approach (especially its econometrically driven $\mathrm{I} / \mathrm{O}$ aspect) for multiregional modeling can be viewed as arising from the following three factors:

(1) stability of technical coefficients $\left(\mathrm{a}_{\mathrm{ij}}{ }^{\prime} \mathrm{s}\right)$;

(2) availability of regional final demand data $\left(\mathrm{C}_{i}\right.$, etc.); and

(3) emphasizing average rather than marginal relationships.

First, since forecasts within an econometric and an embedded econometric model are typically made for 5 -to- 10 year periods, changes in technical coefficients should be expected. At the regional level, annual output, annual industry-specific price change, and annual final demand data are seldom available to address this difficulty. For example, Bourque, et al. were fortunate to have three years $(1963,1967$, and 1972) of data in 
order to incorporate some State-specific coefficient changes into the Washington Projection and Simulation Model. At the multiregional level, projections of coefficient change would have to rely on national projections that might be inappropriate for a given region. ${ }^{6}$

Second, although historical data on industry-specific income are available even at the county level, time-series estimates of final demand, either at the aggregate level (Y.) or at the industry-specific level $\left(\mathrm{Y}_{\mathrm{i}}\right)$, are not available for most regions. Furthermore, generating an historical time series for the components of final demand $\left(\mathrm{C}_{\mathrm{i}}, \mathrm{I}_{\mathrm{i}}, \mathrm{G}_{\mathrm{i}}\right.$, and $\left.\mathrm{E}_{\mathrm{i}}\right)$ may be even more difficult than for total final demand.

Third, when used in impact analysis, the embedded model relies on the average relationships between final demand and intermediate output. For example, if a policy change has the effect of marginally increasing personal income, and therefore consumption, the total consumption change ( $\Delta \mathrm{C}$.) and the industry-specific consumption changes $\left(\Delta \mathrm{C}_{\mathrm{i}}\right)$ may not be distributed in the same relative way that average total consumption (C.) and average industry-specific consumption $\left(\mathrm{C}_{\mathrm{i}}\right)$ are distributed. As a specific example, if income rises due to policy changes, households could save more than average, or households could spend less on food and more on recreation. In the case of consumption, the divergence between marginal and average relationships occurs because the income elasticity of demand is not equal to one for each industry-specific output. To varying degrees, the same divergence can arise in the other components of final demand.

The major advantage of the linked approach for the multiregional modeling of the impacts of policy changes is that the three major limitations of the embedded approach, to a large extent, are overcome. First, since the technical coefficients are used only in estimating initial industryspecific stimuli, the stability of the coefficients over the entire forecast interval is not an issue. Second, final demand data, often unavailable in a consistent, accurate, time series at the State level, are not necessary in the linked approach. Third, the nonunitary elasticities in the multiregional econometric model permit an estimation of the impacts of policy changes, which are not dependent on the average relationships between final demand and intermediate output, when compared to the impacts estimated in the embedded approach. ${ }^{7}$

The major disadvantage of the linked approach is that some of the industrial detail of the pure I/O model is lost. This occurs because the I/O-estimated initial impacts must be summed to the industrial detail of the usually more aggregated econometric model; therefore, it is not possible to forecast economic activity for each of the individual industries in the $\mathrm{I} / \mathrm{O}$ model. However, this disadvantage is to some extent mitigated in the RIMS II-NRIES linked model, which estimates initial impacts (often 50 percent of total impacts) for up to 496 industries. The following section describes the RIMS II-NRIES linked model in detail.

\section{RIMS II-NRIES LINKING APPROACH}

To illustrate the RIMS II-NRIES linking approach, an application 
where a single-region $\mathrm{I} / \mathrm{O}$ model is linked with a multiregional econometric model of the U.S is described. As indicated in the introduction, this application uses three models developed at BEA-the RIMS II regional I/O model, the BEA national I/O tables, and the NRIES multiregional econometric model. Since the RIMS II and NRIES models comprise the basis of this linking technique, a brief overview of their structures is useful before describing the application. A description of the BEA national I/O tables may be found in Ritz (1980).

\section{Overview of the Models}

In response to the growing need for improved techniques for regional impact analysis, the Regional Industrial Multiplier System (RIMS) was designed in the mid-1970's to estimate multipliers for use in determining the secondary single-region impacts of public and private economic development policies on county-defined study areas. ${ }^{8}$ RIMS was capable of providing reliable multiplier estimates without the high cost of gathering survey data. The Regional Input-Output Modeling System (RIMS II) is a refinement of RIMS. The basic differences between RIMS II and RIMS are the use of a more recent national $\mathrm{I} / \mathrm{O}$ table, the use of more detailed data for regionalizing the national I/O table, and improved economic and statistical techniques for estimating multipliers. These improvements have increased the accuracy of the estimated multipliers, have provided greater flexibility in the presentation of results, and have extended the range of applications of the multipliers. For example, for a given industry-specific initial stimulus, while the original RIMS could estimate only the total output and earnings impacts, RIMS II can estimate impacts on 496 affected industries. The capability of RIMS II to estimate the full multiplier matrix (rather than just its column sums as in the original RIMS) is crucial for the various linkages of RIMS II and NRIES discussed below. ${ }^{9}$

The RIMS II estimating procedure can be viewed as a three-step process. In the first step, the national I/O coefficient matrix is made regionspecific by using corresponding 4-digit SIC location quotients (LQ's). The LQ's are used to estimate the extent to which requirements are supplied by firms within the region. For this purpose, RIMS II employs LQ's based on two types of data. According to this mixed-LQ approach, BEA county personal income data, by place of residence, are used for the calculation of LQ's in the service sectors, while BEA earnings data, by place of work, are used for the LQ's in the nonservice sectors. The next step involves estimation of the household row and the household column of the matrix. The household-row coefficients are estimated based on value added-to-gross output ratios from the national $\mathrm{I} / \mathrm{O}$ table: and are introduced into each industry's coefficient column. If it is appropriate to endogenize the household sector, a household column is constructed, based on national consumption and savings rate data, and national and regional tax rate data. The last step in the RIMS II estimating procedure is to calculate multipliers by the Leontief inversion of the previously estimated direct require- 
ments coefficient matrix. This inversion process produces output and earnings multipliers for up to 496 additionally affected industries.

NRIES $^{10}$ is a multiregional econometric forecasting and impact model composed of 51 individual State econometric models, ${ }^{11}$ a national submodel, and explicit interregional linkages. Its primary use is to estimate through time the spatial distribution of impacts resulting from policy alternatives. The model may be used also for medium-range (5-12 year) forecasts of regional economic activity. Within each State model, there are 230 variables estimated annually using ordinary least squares. These include output, employment, wage and nonwage sources of income, State and local government expenditures and revenues, population by age group, and retail sales. Economic activity in a particular State is generally expressed as a function of three types of variables: economic activity in related sectors of the State, economic or demographic interaction among States, and certain nationally determined levels of economic activity.

Examples of the first type of variable include the use of disposable income in an output equation for a local consumption-oriented industry, or the use of output in an employment equation. These types of variables form the internal linkages within each State, similar to single-region econometric models. Interregional linkages among States are explicitly incorporated into the NRIES model through a set of interaction indexes. Based on the gravity-potential concept, these interaction variables represent distance-deflated economic or demographic activity in all States. There are two subcategories of the remaining type of variable in the NRIES model: those national variables that typically exhibit no regional variation and are therefore estimated at the national level ("top-down" element), and those national variables that are expressed as the sum of the variables in the 51 States.

The second type of national variable, the aggregated-State variable, represents a unique feature of NRIES-its "bottom-up" element. Most single-region econometric models are constructed as "satellites" to national econometric models and there is, therefore, a unidirectional relationship between the national economy and the State economy. Changes in economic activity of a particular State have no effect on the national economy. Similarly, in many multiregional models, a top-down approach is often taken, where regional attractiveness variables are used to "shareout" national control totals. Thus, for example, analyzing the impact of alternative distributions of a given amount of Federal aid or expenditures is difficult in the top-down multiregional models since the national control totals remain the same. In contrast to the unidirectional focus of most other single-region and multiregion models, national and State economic activity in NRIES is simultaneously determined. Regional economic activity determines some national economic activity, which in turn has a secondary effect on regional activity.

Overview of Application

RIMS II and NRIES were used to determine the impacts of Local Public 


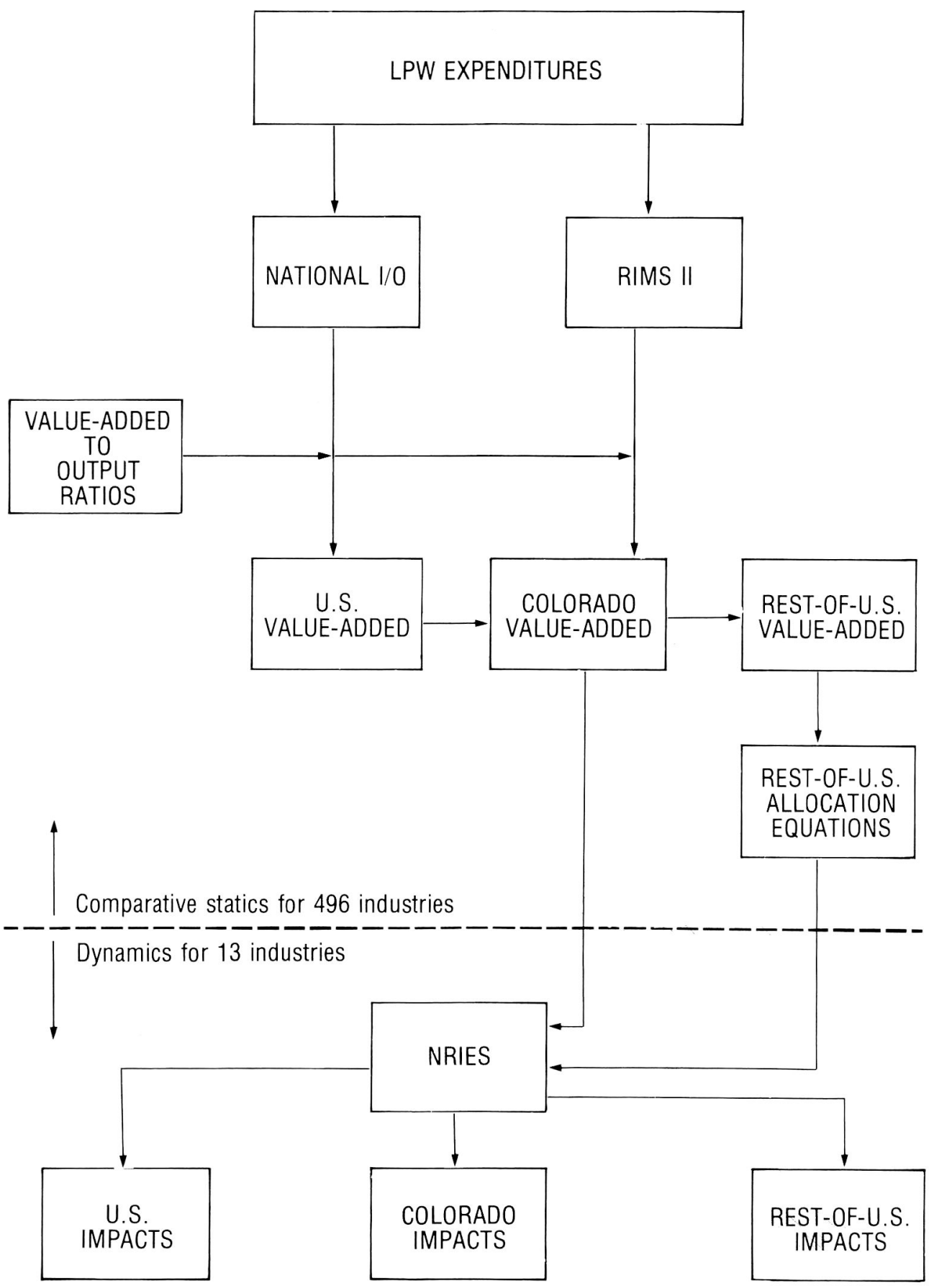

Figure 1. Derivation of the Spatial Distribution of Impacts of Local Public Works Expenditures in Colorado 
Works (LPW) expenditures in the Denver SMSA on the economies of Colorado and the Nation. ${ }^{12}$ The LPW expenditures in the Denver SMSA by project type were obtained from the Economic Development Administration; these expenditures are tabulated by I/O-defined construction activity. The majority of these expenditures were associated with constructing new sewer facilities. Figure 1 depicts the process by which economic impacts of the LPW expenditures were derived. The LPW expenditures were used as inputs into RIMS II and the national I/O tables, and then expenditure-to-output conversion equations were used to derive industry estimates of the change in output produced by the LPW expenditures. These first-round or initial changes in output for Colorado were used as inputs into NRIES to determine the total impact on Colorado, while a gravity concept was used to allocate these output changes for the rest of the U.S. to the remaining 50 States. NRIES was run over a 1978-84 forecast period with these adjustments, to provide estimates of the total impacts of the LPW expenditures on Colorado and the remainder of the United States. The following discussion describes this procedure in detail.

RIMS II and National I/O Components-The first step in the analysis involved the conversion of LPW expenditures as used in the RIMS II model and the national I/O table into value-added changes by industry to be used by NRIES. This step was necessary, since the most important measure of economic activity in NRIES is value added by industry, and the LPW construction expenditures, by themselves, represent changes in final demand sales to the government sector. The following equation shows how the construction expenditures were translated into national output changes by industry.

$$
\Delta Q_{i}^{n}=\left(Q_{i} / X_{i}\right)^{n} \cdot \underset{j}{\Sigma} b_{i j}^{n} \cdot \Delta Y_{j}
$$

where:

$\Delta Q_{\mathrm{i}}^{\mathrm{n}}=$ national output (GNP definition) change in industry $\mathrm{i}$.

$\left(\mathrm{Q}_{\mathrm{i}} / \mathrm{X}_{\mathrm{i}}\right)^{\mathrm{n}}=$ national ratio of output (GNP definition) to output (I/O definition) for industry i.

$b_{\mathrm{ij}}^{\mathrm{n}}=$ direct and indirect national requirements for the output ( $\mathrm{I} / \mathrm{O}$ definition) of industry i used as input for construction type $\mathrm{j}$.

$\Delta Y_{j}=$ dollar amount of final demand change for construction type j. 
In equation (11), the construction expenditures $\left(\Delta Y_{j}\right)$ are viewed as a change in final demand, which increases the level of national output (GNP definition) or value added $\left(\Delta Q_{i}^{n}\right)$. The levels of the industry-specific changes in output were estimated using national $\mathrm{I} / \mathrm{O}$ coefficients, $\mathrm{b}_{\mathrm{ij}}^{\mathrm{n}}$, and national ratios of value added $\left(Q_{i}\right)$ to output $\left(\mathrm{X}_{\mathrm{i}}\right)$ from the national $\mathrm{I} / \mathrm{O}$ tables.

An equation similar to the above was used to estimate the size of output changes in Colorado.

$$
\triangle Q_{i}^{c}=\left(Q_{i} / X_{i}\right)^{n} \cdot \underset{j}{\Sigma} b_{i j}^{c} \cdot \Delta Y_{j}
$$

where:

$\triangle Q_{\mathrm{i}}^{\mathrm{c}}=$ Colorado output (GNP definition) change in industry $\mathrm{i}$.

$\mathrm{b}_{\mathrm{ij}}^{\mathrm{c}}=$ direct and indirect Colorado requirements for the output (I/O definition) of Colorado industry i used as input for construction type $\mathrm{j}$.

In Colorado I/O coefficients, $b_{\mathrm{ij}}^{\mathrm{c}}$, were estimated by RIMS II. The other terms in equation (12) are defined as in equation (11), and the interpretation of the above equation is similar to that for equation (11). The difference between changes in national and Colorado output equals the output changes in the rest of the United States $\left(\triangle Q_{i}^{r}\right)$. The initial output changes can be summarized in the following two identities:

$$
\begin{aligned}
& \underset{j}{\Sigma} \Delta Y_{j}=\underset{i}{\Sigma} \Delta Q_{i}^{n}+\text { IMPORTS } \\
& \underset{j}{\Sigma} \Delta Q^{n}={\underset{i}{\Sigma}}_{j} \Delta Q_{i}^{c}+\underset{i}{\sum} \Delta Q_{i}^{r}
\end{aligned}
$$

The first identity states that changes in construction final demand are equal to changes in domestic and foreign output, and the second identity states that changes in national output are equal to the sum of output changes in Colorado and in the rest of the United States.

NRIES Components-.For Colorado, the inputs into NRIES consisted of these 1972-dollar changes in output for nine of NRIES' industries. As inputs into NRIES for the rest of the United States, the RIMS II-generated initial changes in output by industry for the rest of the U.S. were aloocated among the remaining States including the District of Columbia. It was assumed that two factors determine an individual State's share of the total rest of U.S. output changes: relative proximity to the point of initial 
stimulus (Colorado), and the relative importance of each State's industries to the national industry totals. Thus, first, the simple linear distance between the population center of Colorado and the population centers of the remaining 50 States was obtained. Second, 1978 output values for nine industries were obtained for each State and the United States (net of Colorado) from a NRIES baseline solution. For each industry, the share of national (net of Colorado) output accounted for by each State was deflated by the distance factors. These distance-deflated 1978 output values for each of the nine industries for the remaining 50 States were used as allocation coefficients to apportion the rest-of-the U.S. output changes among the 50 States. The following equations depict this procedure:

$$
\begin{aligned}
\Delta \mathrm{X}_{\mathrm{ij}}= & \frac{\mathrm{X}_{\mathrm{ij}} / \mathrm{d}_{\mathrm{cj}}}{\mathrm{m}} * \Delta \mathrm{X}_{\mathrm{i}, \text { rus }} \\
& \underset{\substack{\mathrm{j}=\mathrm{l} \\
\mathrm{j} \neq \mathrm{C}}}{\mathrm{i}} \mathrm{X}_{\mathrm{ij}} / \mathrm{d}_{\mathrm{cj}}
\end{aligned}
$$

or

$\Delta \mathrm{X}_{\mathrm{ij}}=\mathrm{A}_{\mathrm{ij}} * \Delta \mathrm{X}_{\mathrm{i}, \text { rus }}$

$\Delta \mathrm{X}_{\mathrm{ij}}$, the changes in output for industry $\mathrm{i}, \mathrm{i}=1, \ldots, 9$ and State $\mathrm{j}, \mathrm{j}=1, \ldots$, $M(j \neq c)$ is the product of two components. First, the 1978 baseline solution output values for industry $\mathrm{i}$, State $\mathrm{j}\left(\mathrm{X}_{\mathrm{ij}}\right)$ are deflated by the distance from Colorado (c) to State $\mathrm{j}\left(\mathrm{d}_{\mathrm{cj}}\right)$, and weighted by the sum of the distancedeflated output values in all States other than Colorado. The result is then multiplied by the rest-of-U.S. (rus) output changes in industry $\mathrm{i}\left(\Delta \mathrm{X}_{\mathrm{i}}\right.$, rus $)$. Note that the sum of the allocation coefficients (the $A_{i j}$ 's) over the 50 States equals one, so that the sum of the industry share distance-deflated output changes over the 50 States equals the total rest-of-U.S. output changes by industry. That is,

$$
\sum_{\substack{j=1 \\ j \neq c}}^{M} A_{i j}=1
$$

and therefore,

$$
\begin{aligned}
& \mathrm{M} \\
& \Sigma \Delta \mathrm{X}_{\mathrm{ij}}=\Delta \mathrm{X}_{\mathrm{i}, \text { rus }} \text { for every industry } \mathrm{i}, \mathrm{i}=1, \ldots, 9 \text {. } \\
& j=1 \\
& \mathrm{j} \neq \mathrm{c}
\end{aligned}
$$


To estimate the impact of the LPW expenditures (converted to 1972 dollar changes in output) for Colorado, the United States, and the rest of the Nation, NRIES was first simulated over the 1978-84 forecast period to produce a "most likely scenario" of economic growth for States in the United States. This simulation, which will be referred to as the baseline solution, provided the basis for comparison with an alternative solution in which the $1978 \mathrm{LPW}$-generated construction stimulus to Colorado was introduced. The impacts caused by the LPW construction program were derived by calculating the differences between the forecasted values of certain key economic variables in the baseline and alternative solutions for Colorado, the United States, the remainder of the United States, and for the eight BEA multistate regions. The resultant impacts reflect the effects of interregional, as well as dynamic linkages within NRIES.

Table 1 presents the impacts of the LPW construction grants on total real output in the United States, Colorado, the rest of the United States, and the eight BEA regions. ${ }^{13}$ For 1978 , the year of initial stimulus, the total effect on real output in the Nation (GNP) is significantly greater than the size of the initial LPW stimulus. In particular, a $\$ 15.6$ million change in real output for the United States associated with the LPW program in Denver, produces a national total impact of $\$ 24.1$ million in economic activity in 1978. Of that total impact, $\$ 23.6$ million, or 98 percent, occurs in Colorado (versus an 83-percent share of the initial change in U.S. output), while only $\$ 0.53$ million in economic activity is generated outside Colorado from a $\$ 2.7$ million initial change in rest-of-U.S. output. ${ }^{14}$ Thus, the size of the stimulus to Colorado was so great as to induce outmigration from other States into Colorado.

In 1979, the impact on GNP is about one-eighth as large as in 1978. The impact on Colorado real output is almost $\$ 6.6$ million, while the remainder of the United States actually loses about $\$ 3.6$ million in output, relative to the baseline. Throughout the remainder of the forecast period, the total impact on GNP steadily diminishes, with Colorado returning to its baseline growth trends beginning in 1981. The total impact over the entire forecast period, 1978-84, is $\$ 31.3$ million in the Nation, 97 percent of which occurs in Colorado.

Table 1 also presents the real output impacts on the eight BEA regions. As expected, the impact for 1978 is largest in the Rocky Mountain region (of which Colorado is a part), followed by impacts in adjacent regions: the Southwest and Plains. The Far West region, although adjacent to the Rocky Mountain region, does not experience as great an impact as might be expected. This is not surprising, however, since industrial structure, as well as proximity to Colorado, determines the size of the impact, as discussed earlier. California, the largest State in the Far West region, accounts for a much larger share of the national services industry total than of the national manufacturing industry total, and the size of the initial change in rest-of-U.S. output was much greater for manufacturing durables than for services. 
Table 1.

Output Impacts* From LPW Expenditures in Denver** (Millions of 1972 dollars)

\begin{tabular}{|c|c|c|c|c|c|c|c|c|}
\hline State & 1978 & 1979 & 1980 & 1981 & 1982 & 1983 & 1984 & Total \\
\hline United States & 24.15 & 3.04 & 1.25 & 1.21 & 1.00 & 0.50 & 0.11 & 31.27 \\
\hline Colorado & 23.63 & 6.65 & 1.59 & -0.24 & -0.54 & -0.43 & -0.24 & 30.43 \\
\hline Rest of the U.S. & 0.53 & -3.62 & -0.34 & 1.45 & 1.54 & 0.93 & 0.34 & 0.84 \\
\hline \multicolumn{9}{|l|}{ BEA Regions } \\
\hline New England & -0.26 & -0.29 & - & - & - & - & - & -0.79 \\
\hline Mideast & -0.92 & -2.52 & -1.29 & -0.54 & -0.11 & - & - & -5.31 \\
\hline Great Lakes & -0.25 & -0.61 & -0.19 & 0.16 & 0.26 & 0.23 & 0.14 & -0.26 \\
\hline Plains & 0.49 & - & 0.28 & 0.26 & 0.20 & 0.14 & 0.10 & 1.57 \\
\hline Southeast & 0.19 & -0.76 & - & 0.44 & 0.41 & 0.24 & - & 0.57 \\
\hline Southwest & 0.95 & 0.40 & 0.39 & 0.36 & 0.24 & - & - & 2.46 \\
\hline Rocky Mountain & 23.81 & 6.70 & 1.64 & -0.18 & -0.49 & -0.40 & -0.21 & 30.87 \\
\hline Far West & 0.12 & - & 0.57 & 0.76 & 0.50 & 0.19 & - & 2.15 \\
\hline
\end{tabular}

*Numbers whose absolute value is less than $\$ 1$ million are not significantly different from zero in the NRIES model.

**These total real output impacts result from initial output changes of $\$ 12.9$ million in Colorado; of $\$ 15.6$ million in the U.S.; and of $\$ 2.7$ million in the rest of the U.S. 
Insignificant impacts occur in the New England, Great Lakes, and Southeast regions, due to their relative distance from Colorado. Significant negative impacts occur in the Mideast region, due both to its industrial structure and to its oversupply of labor. Finally, over the entire forecast period, significant positive impacts occur in the Rocky Mountain, Southwest, Far West, and Plains regions due to their close proximity to Colorado.

\section{SUMMARY}

The purpose of this paper has been to describe the various approaches to combining the advantages of $\mathrm{I} / \mathrm{O}$ models with those of econometric models in a multiregional setting. Two approaches and their advantages and limitations were discussed-that of embedding an $\mathrm{I} / \mathrm{O}$ model in a multiregional econometric model, and that of linking an I/O model with a multiregional econometric model. It was indicated that the embedding approach contains elements of the linking approach inasmuch as certain outputs from the $\mathrm{I} / \mathrm{O}$ model, in combination with various exogenous variables, do in fact enter into the econometric specifications of final demand components. However, because of the sparsity of time series estimates of regional final demand components, and because of the difficulty in projecting changes in regional technical coefficients, the embedding approach suffers from a number of limitations not shared by the linking approach.

An application of the linking approach using three models developed at BEA-RIMS II, the BEA national I/O table, and NRIES—was described. This application focused on using a single-region I/O model and a national $\mathrm{I} / \mathrm{O}$ table, and linking them to a multiregional econometric model to evaluate how a program affecting one State impacts on that State as well as on all other States in the Nation.

An interesting extension of this methodology would be to use 51 RIMS II I/O models, one for each State and the District of Columbia, and to link them with NRIES, to evaluate how a particular multistate program affects the entire U.S. That is, assuming that the impacts of an exogenous final demand change occurring in every State are required, a RIMS II I/O model could be constructed for each State to indicate the initial impacts of the final demand change at the 496-industry level. Then, aggregating this information to the industry level of NRIES, NRIES could be used to estimate the total-direct, indirect, induced, and interregional-impacts of the final demand change over time.

\section{FOOTNOTES}

\footnotetext{
${ }^{1}$ Bolton (1979) and Bolton and Chinitz (1980) provide overviews of multiregional modeling. For a description of various types of multiregional models, see Adams and Glickman (1980), Dresch and Updegrove (1978), Holmer (1980), Polenske (1980), and Stevens and Trainer (1980); for references to regional models in general, see the bibliographies in Ballard, Gustely, and Wendling (1980) and Cartwright, et al. (1981).
}

${ }^{2}$ Bolton and Chinitz (1980, p. 43) make this point, for example.

${ }^{3}$ This approach has been employed at the singleregion level-Glickman (1977, pp. 170-180) —and at the multiregion level by the authors.

${ }^{4}$ The need to convert output changes into value-added changes arises because of the difference in the economic accounting units used in the $\mathrm{I} / \mathrm{O}$ and econometric mod- 
els. Output (I/O definition) is similar to total industry sales; output (GNP definition) is equal to value added, and therefore, excludes intermediate purchases. In this paper, the $\mathrm{I} / \mathrm{O}$ definition of output is denoted by $\mathrm{X}$ and the GNP (value added) definition of output is denoted by $Q$.

${ }^{5}$ In the new version of the Washington Projection and Simulation Model, consumption is also disaggregated into four sectors-durables, nondurables, services, and other.

${ }^{6}$ The issue of coefficient stability applies as well to interregional trade coefficients in a multiregional embedded approach model. However, this difficulty can be overcome (as it is in the linked approach) by estimating dynamic interaction indexes based on a gravity variable. The weaknesses of the gravity approach are, of course, recognized.

${ }^{7}$ Since initial impacts are estimated with an $\mathrm{I} / \mathrm{O}$ model, the linked approach is dependent on both the average interindustry relationships $\left(\mathrm{a}_{\mathrm{ij}}\right)$ and the average relationship between industry-specific output $\left(\mathrm{X}_{\mathrm{i}}\right)$ and value added $\left(Q_{1}\right)$. However, unlike the embedded approach these dependencies hold only for the calculation of initial impacts but do not hold for the entire forecast interval.

${ }^{8}$ For a more complete discussion, see Cartwright, et al (1981).

${ }^{9}$ For the linkages discussed in this section of the paper, the full multiplier matrix was estimated using a revised version of RIMS, which used several techniques from RIMS II. RIMS II had not been completely developed when research began on linking BEA's regional I/O and econometric models. In order to simplify the presentation, the term, RIMS II, has been used throughout this paper.

${ }^{10}$ For a more complete discussion, see Ballard, Gustely, and Wendling (1980).

${ }^{11}$ For simplicity, the District of Columbia is referred to as a State.

${ }^{12}$ Portions of this subsection were excerpted from Ballard, Cartwright, Gustely, and Kort (1980). The RIMS II model, by itself, was used also to estimate the impacts on Denver County and the Denver SMSA, according to the methodology presented in Cartwright (1979).

${ }^{13}$ Numbers in table 1 whose absolute value is less than $\$ 1.0$ million are not significantly different from zero in the NRIES model. This application of the RIMS IINRIES linking methodology incorporates an initial stimulus, the size of which is perhaps at the lower end of the threshold level of NRIES' sensitivity to impacts. While a larger initial stimulus would have produced more significant impacts outside Colorado, the present application nevertheless serves to illustrate the RIMS II-NRIES linking methodology.

${ }^{14}$ The differences between the RIMS II-generated initial rest-of-U.S. impact and the final NRIES total impact reflects interregional linkages in the econometric model. The increased demand in Colorado in the impact solution relative to the baseline attracts economic activity away from other States. Since RIMS II is not an interregional I/O model, it cannot capture these additional effects.

\section{REFERENCES}

Adams, F. Gerard, and Glickman, Norman, Modeling the Multiregional Economic System, (Lexington, MA: D. C. Heath), 1980.

Almon, Clopper; Buckler, Margaret; Horowitz, Lawrence; and Reimbold, Thomas, 1985: Interindustry Forecasts of the American Economy, (Lexington, MA: D.C. Heath), 1974.

Ballard, Kenneth; Gustely, Richard; and Wendling, Robert, The National-Regional Impact Evaluation System; Structure, Performance, and Application of a Bottom-Up Interregional Econometric Model, (Washington, DC: U.S. Department of Commerce), 1980.

; Cartwright, Joseph; and Kort, John, "Developing a Spatially Comprehensive Impact Modeling System: A Feasibility Study," (unpublished paper), 1980.

Bodkin, Ronald, "A Large-Scale Input-Output Econometric Model of the Canadian Economy (CANDIDE)," in, Advances in Input-Output Analysis, ed., Karen Polenske and Jiri Skolka, (Cambridge, MA: Ballinger), 1976, pp. 27-44.

Bolton, Roger, "Multiregional Models in Policy Analysis," paper presented at a conference on Modeling the Multiregion Economic System, Philadelphia, PA, June 14-15, 1979.

and Chinitz, Benjamin, "Multiregional Modeling," paper presented at the American Economic Association meetings, Denver, Colorado, September 6, 1980.

Bourque, Philip; Conway, Richard; and Howard, Charles, The Washington Projection and Simulation Model, (Seattle, WA: University of Washington), 1977.

Cartwright, Joseph V., "Estimating the Spatial Distribution of Program Impacts within Metropolitan Areas," paper presented at the Southern Regional Science Association meetings, Nashville, Tennessee, April, 1979.

; Beemiller, Richard; and Gustely, Richard, Regional Input-Output Modeling System: Estimation, Evaluation, and Application of a Disaggregated Regional Impact Model, (Washington, D.C.: U.S. Department of Commerce), 1981.

Dresch, Stephen and Updegrove, Daniel, IDIOM: A Disaggregated Policy-Impact Model of the U.S. Economy, (New Haven, CT: Institute for Demographic and Economic Studies, Inc.), 1978.

Glickman, Norman J., Econometric Analysis of Regional Systems, (New York: Academic Press), 1977.

Holmer, Martin, "Urban, Regional and Labor Supply Effects of a Reduction in Federal Individual Income Tax Rates," in The Urban Impacts of Federal Policies, ed. Norman Glickman (Baltimore, MD: The Johns Hopkins University Press), 1980, pp. 494-511.

L'Esperence, Wilford; King, Arthur; and Sines, Richard, "Conjoining an Input-Output with an Econometric Model of Ohio," Regional Science Perspectives, (2), (1975), pp. 54-77.

Polenske, Karen, The U.S. Multiregional Input-Output Accounts and Model, (Lexington: D.C. Heath), 1980.

Preston, Ross S., The Wharton Annual and Industry Forecasting Model, (Philadelphia, PA: Wharton School). 1972 .

- "The Wharton Long-Term Model: InputOutput Within the Context of a Macro Forecasting Model," International Economic Review, Vol. 16, No. 1, (Feb. 1975), pp. 3-19.

Ritz, Philip M., Definitions and Conventions of the 1972 Input-Output Study, Bureau of Economic Analysis staff 
paper \#80-034, (Washington, D.C.: U.S. Department of Commerce), July 1980.

Seguy, Rogelio M., and Ramirez, Jesus, "The Use of Input-Output Analysis in an Econometric Model of the Mexican Economy," Annals of Economic and Social Measurement, Vol. 4, No. 4, (Fall, 1975), pp. 531-552.

Stevens, Benjamin, and Trainer, Glynnis, "Error Generation in Regional Input-Output Analysis and its Implications for Nonsurvey Models," in Economic Impact Analysis: Methodology and Applications, ed. Saul Pleeter (Boston: Martin Nijhoff), 1980, pp. 68-84. ; Treyz, George; and Kindahl, James, "Conjoining an Input-Output Model and a Policy Analysis
Model: A Case Study of the Regional Economic Effects of Expanding a Port Facility," unpublished paper, 1980

Treyz, George; Williams, Ray; DuGuay, G.E.; Stevens, Benjamin; and Friedlaender, Ann, "An Overview of the Massachusetts Economic Policy Analysis (MEPA) Model," paper presented at the Harvard/MIT Joint Center for Urban Studies conference on, An Assessment of the State of the Art in Regional Modeling, Cambridge, MA, April 23-25, 1980.

, "Design of a Multiregional Policy Analysis Model, Journal of Regional Science, Vol. 20, No. 2, (May 1980), pp. 191-206. 